\title{
The effect of myocardial fibrosis on left ventricular diastolic function assessed by non- invasive cardiac magnetic resonance and echocardiography
}

\author{
Zahra Alizadeh Sani, Azarakhsh Babolian*, Pedram Golnari \\ From 15th Annual SCMR Scientific Sessions \\ Orlando, FL, USA. 2-5 February 2012
}

\section{Background}

Accumulating evidence indicates that myocardial fibrosis contributes to the pathogenesis of diastolic dysfunction. However, investigating this issue has long been hampered by lack of suitable methodology. We aimed to define the effect of fibrosis on left ventricular diastolic function, using cardiac magnetic resonance (CMR) and Doppler echocardiography.

\section{Methods}

Ninety one eligible subjects undergoing cardiac structural and functional assessment with LGE-CMR and Doppler echocardiography were investigated. Left ventricular function, volumes, myocardial thickness, left atrial volume, wall motion score index (WMSI) and the extent of LGE were assessed using CMR. Mitral early diastolic peak (Ewave) and late peak (A-wave) velocities, E/A ratio, deceleration time (DT) of mitral early velocity, early diastolic mitral annulus peak velocity was measured by echocardiography, and ratio of transmitral diastolic peak velocity to the mitral annular diastolic peak velocity (E/E') was calculated. Classification of diastolic function as normal, mild dysfunction (impaired relaxation), moderate dysfunction (pseudonormal), and severe dysfunction (restrictive filling pattern) was performed according to standard criteria. The E/E ratio was used to estimate LV filling pressures.

\section{Results}

The majority (90\%) of subjects with normal diastolic function exhibited no or minimal fibrosis (median LGE

Shaheed Rajaie Cardiovascular Medical \& Research Center, Tehran University of Medical Sciences, Tehran, Islamic Republic of Iran score, 0 ; interquartile range, 0 to 0 ). The prevalence of LGE positivity by diastolic filling pattern was $11.8 \%$ in impaired relaxation, $100 \%$ in pseudonormal, and $75 \%$ in restrictive filling $(\mathrm{P}<0.001)$. LGE score significantly and progressively increased with increasing severity of filling impairment, reaching 5 (interquartile range, 0.59.75) in patients with restrictive filling pattern $(\mathrm{P}<0.001)$. LGE was observed in $80 \%$ of patients with ischemic cardiomyopathy and $26.3 \%$ of patients with nonischemic cardiomyopathy, but only in $3.6 \%$ of patients with repaired tetralogy of Fallot and none of patients with simple congenital heart disease $(\mathrm{P}<0.001)$. LGE score progressively increased with increasing left ventricular filling pressure estimated by tissue Doppler imaging-derived $E / E(P<0.001, r=0.455)$. However it did not have any significant correlation with other echocardiographic diastolic function indices, such as $\mathrm{E}$ velocity, A velocity, and DT. Multiple linear regression showed LGE score $(\mathrm{P}=0.026, \mathrm{~B}=0.251)$ and WMSI $(\mathrm{P}<0.001, \mathrm{~B}=0.422)$ to be positively predictive for $\mathrm{E} / \mathrm{E}$ value.

\section{Conclusions}

Severity of myocardial fibrosis by LGE significantly correlates with the degree of diastolic dysfunction in a broad range of cardiac conditions, and among diastolic echocardiographic indices E/E may provide more valuable insight to this severity. Noninvasive assessment of myocardial fibrosis may provide valuable insights into the pathophysiology of left ventricular diastolic function and therapeutic response. 


\section{Funding}

This project was not funded.

Published: 1 February 2012

doi:10.1186/1532-429X-14-S1-037

Cite this article as: Sani et al: The effect of myocardial fibrosis on left ventricular diastolic function assessed by non-invasive cardiac magnetic resonance and echocardiography. Journal of Cardiovascular Magnetic Resonance 2012 14(Suppl 1):O37.

Submit your next manuscript to BioMed Central and take full advantage of:

- Convenient online submission

- Thorough peer review

- No space constraints or color figure charges

- Immediate publication on acceptance

- Inclusion in PubMed, CAS, Scopus and Google Scholar

- Research which is freely available for redistribution

Submit your manuscript at www.biomedcentral.com/submit 